\title{
MESSAGE FROM THE COLLEGE PRESIDENT - DR NEALE FONG
}

\section{Dr Neale Fong FCHSM}

President of Australasian College of Health Service Management

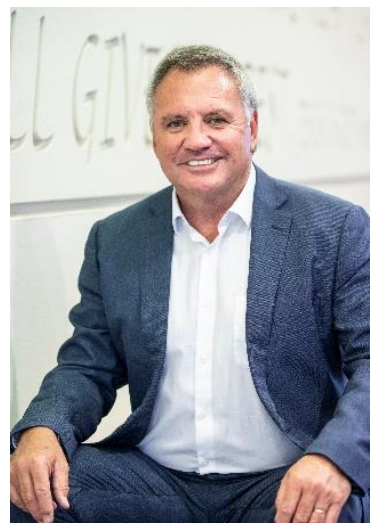

Leadership and management spawn numerous catchphrases to assert what is important "right now". Resilience. Leaning in, or out. Authenticity. Balance. Agility. As a College for health managers and leaders, our clear challenge is to look past the "right now" and create the best platform to support our members through what we hope will be their lengthy career and positive contribution to the health of their communities.

In the past year the College has introduced a credentialling approach for health leaders which is inclusive of any and all of the latest leadership theories whilst acknowledging that real and substantial contributions to the health of the community is an iterative process requiring the commitment of individual leaders over long careers spanning decades. Our vision is "Better Leadership. Healthier Communities." Our body of services is directed at supporting our members to achieve this vision.

\section{WHY CERTIFICATION?}

At the very foundation of the notion of what constitutes a profession is a body of knowledge and skills that requires attainment and continuous improvement. The individual leader is supported by an external body (the College) that describes that body of knowledge and skills and creates a framework for the individual to point to how they personally are committing to lifelong learning and development.

In the health sector certification in a profession is an employment currency that has traditionally excluded the leaders and managers. Through the introduction of these credentials, the College supports members and future members to have their body of knowledge and skills recognised and provides the platform for continuing development.

The role of consumer expectation plays a role in the need for the College credentialling system. Consumers expect a professional and independent recognition of the capability of the senior people who develop, lead, manage and have responsibility for their health facilities and services.

\section{OUR CHALLENGE TO OUR CHM'S AND CHE'S}

Implicit in this Certification system is that it is very important that the College's Certified Health Manager and Certified Health Executives use their postnominals in communications within the health sector, talk about the College's work in supporting the profession and "live" the vision of committing to lifelong learning as part of a community of leaders.

Over the past difficult 18 months the College itself has leaned into this attribute of community which goes beyond the triteness of "we are all in this together". I have been proud and delighted to see how many of our members stepped up to support each other during this time and have been glad to harness that collegiate good will in developing both free and more importantly more opportunities for members to come together in small and large groups to listen and learn.

This journal continues to be an excellent and informative part of health leaders' journeys. We are thankful for the partnership with SHAPE and commend members' contributions to this publication; another way to continue the life-long learning that is so necessary in meeting the challenges of the health and community care sectors.

Dr. Neale Fong FCHSM

President Australasian College of Health Service Management 